\title{
FACTORS AFFECTING MERGERS AND ACQUISITIONS IN THE EUROPEAN UNION
}

\section{Kaspars Mucenieks}

Mag. oec.

\begin{abstract}
Global economic processes create a situation that companies must plan their activities strategically and in the long term to ensure the competitiveness of the company's survival. Mergers and acquisitions (M\&A) is a business development tool whose primary task is to ensure the company's sustainable growth. This is facilitated by factors such as increased competition, technological development, modernization, restructuring of production, a change in strategy, etc. The apparent increase in the number of $M \& A$ in recent decades has improved overall knowledge and understanding of due diligence. To make the right decisions about M\&A of the company, the owner of the shares and the sale of shares through the future development plans, as well as through reorganisation measures, it is important to make the rating within the relevant market factors, economic and industry analysis, as well as with the business principles of qualitative factors and associated with cash flow and profitability in the financial future of the related factor analysis. This paper examines the main factors in the M\&A process. The task of this document is to provide a more complete understanding of the factors affecting M\&A.
\end{abstract}

Keywords: merger, acquisition, due diligence, integration, value

\section{Introduction}

Mergers and acquisitions (M\&A) represent a popular strategy used by companies for many years. In fact several reviews have shown that, on average, companies create little or no value by making acquisitions (Hitt, King, Krishnan, Makri, Schijven, Shimizu, \& Zhu, 2009, p. 524). Economists and venture capitalists are predicting an increase in $M \& A$ as nowadays organizations want to grow their market share and presence by building synergies (Jain, 2014, p. 97). M\&A in a broad sense can mean a number of different transactions ranging from buying and selling companies, the concentration between companies, alliances, cooperation and joint ventures in the formation of companies. Schuler and Jackson (2001, p. 240) argued that a broad definition of $M \& A$ could be used confusion and misunderstandings, because it covers everything from pure merger to strategic alliance. In this paper the definition of $M \& A$ will be used in the narrow sense as purchases as purchases of shares or assets on another company to achieve full management and operational impact. M\&A of the 
company is in particular because the relevant information about the target company is not available to the acquirer (Very \& Schweiger, 2001, p. 12). Although the M\&As are motivated by the expected synergy between the target and the acquiring firms, some mergers are successful while others are not (Canina, Jin-Young, Qingzhong, 2010, p. 82). In the last years, markets are characterized by disruptive changes as well as M\&A activities (Kernstock, Brexendorf, 2012, p. 170). M\&A are undertaken on the assumption that the combined company will have a greater value than the two companies alone (Vazirani, 2013, p. 82). M\&A processes are complex processes with many challenges in the pre-deal and post-deal phases.

\section{Factors affecting mergers and acquisitions}

In the present context of the European Single Market and the globalization among economies, mergers and acquisitions represent the means by which companies increase their competitional capacity (Banulescu, Popescu-Cruceru, Leuciuc, 2012, p. 209). A representative review of the extant research on $M \& A$ over the last 15 years produced a list of the most common value studied. The review of the academic literature consisted of computerized and manual questions about the published research reports.

The value of the company will reflect the contents of the solution for the various parameters that are evaluated for its operation:

- market share and competitive position stability;

- income;

- investment need;

- operational efficiency;

- the tax burden;

- cash flow management;

- the degree of risk.

The company is in the process of evaluating a company's or individual's direction value. Most often, the aim of evaluation is the determination of the market value. To successfully plan the further development of the company, merger of the whole or part of the company, buying and selling, capital injections in new directions of activity, new investment in the current transaction, as well as in other cases, the company carried out the evaluation. Company rating as it also helps entrepreneurs, potential investors to evaluate the financial situation and make the right investment decisions. Company evaluation process results in the entire company or its separate actions in terms of value for money. An organization can have multiple values depending on the scoring target. There are different types of evaluation:

- market value; 
- the value of an investment;

- the value of company workers;

- salvage value;

- balance sheet value, etc.

The value of the company is composed of several factors. The first the ability of a company to make money, the second - company assets that belong to the company, i.e., the material base, the third - goodwill: the word, the technology used, a market where it's working, staff. Results also suggest that the asset specificity discount in the target return is more pronounced if target firms are financially distressed. Asset specificity of a firm is an important determinant of the firm's value (Kim, 2018, p. 378). Operating cash flow increases the company's turnover and other revenue associated with the core, but it reduces production, administration, sales and other operating costs. The difference between revenue and the cost is the company's profit before depreciation deductions, interest payments and taxes (EBITDA), so the higher the EBITDA is obtained; the higher cash flow from operating activities the company is obtained. This variable directly affects the company's turnover and costs. Developing and directing profitable products and running costs, the company increased cash flow from EBITDA. In Latvia, to determine the value of the company, also uses EBITDA factor. EBITDA is the base business profitability, which usually take into account the buyer (Pratt, Reilly, Schweih, 1996, p. 338). Financial analysis of the company's important role in the M\&A process management. Analysis tasks: to determine the effectiveness of the company's activities; identify potential business development directions. Analysis of economic activities is a prerequisite for planning. So the company can plan their actions in the future, it is necessary to analyse the results of the previous operation. Nowadays, more and more business owners and managers understand that company's evaluation is a tool used to assess how successful the company implements its strategy, and what are the main elements of its competitiveness.

\section{Due diligence review}

From a theoretical point of view, due diligence process is largely in line with the prospect organizational learning theory (Barkema \& Schijven, 2008, p. 599), more explicitly teaching (March 1991, p. 80). Under this perspective, the company learns with each of them and can transfer this learning effect to future $M \& A$. Challenge the $M \& A$ process is such that the process is more complicated than the operating company, for example, production, pricing, distribution, etc. Traditional legality checking process is primarily focused on tangible assets or documents relating to the operation of the company 
resulting in a legal, accounting and tax issues (Harvey \& Lusch, 1995, p. 19). Consequently, the main legality checks are still financial and although the results of $M \& A$ transactions show a lack of traditional credibility testing approach (McGrady, 2005, p. 21). Business consultants are based on regular experiences based on best practices, using experience and feedback from projects with your customers. Look for factors that are mostly simplified and suitable for a large number of $M \& A$. The main role of the due diligence process for $M \& A$ is to evaluate the benefits and responsibilities of $M \& A$ of the company with the analysis methods relating to the company's past, present and future are expected to purchase business. An in-depth examination of business process occupies a significant role in the M\&A. If this process is missing, there is a great possibility that in the future it could cause bad financial indicators of the company. It is important to create a management team that will make due diligence process, a team that evaluated the company systematically both before and after M\&A. Due diligence process see the problems that must be resolved in the company's $M \& A$ to be successful. The due diligence includes: financial risk analysis, the financial position of the company and the determination of the value, legal risk analysis, tax risk analysis and evaluation, financial indicators for conditions where reliable information is difficult to obtain, risk analysis staff. Often M\&A require the national regulator or another third-party authorization. Restrictions may be imposed by the competition law; the transaction may be required for other government agencies to agree. Due diligence indicates the existing and potential liabilities. With an indepth exploration of the company is evaluating whether the agreements contain specific restrictions or obligations. Due diligence is in the process of acquiring the company, which is testing a company takeover object for determining whether the proposed transaction, the justification is based on the financial and strategic indicators. Need to define questions, which is acquiring a company must establish a plausibility check (Cullinan, Roux, Weddigen, 2004, p. 101). The operation and development of the company is associated with future prospects, opportunities, risks and uncertainties, the company's performance depends on the skills to use modern business management techniques and tools. The findings suggest that identifying and prioritizing relevant fields in the context of integration would improve the resource allocation decision and the effectiveness of post-integration evaluation (Chang, Chang, 2014, p. 39). Most existing research on M\&A of the results of the study results on the company's profitability, which is based on stock prices. However, there are studies that use information about the company's accounting results in annual reports. D. Mueller was one of the first to use accounting data analysis of mergers and acquisitions for evaluation. He analysed the merger transactions of 247 from 1962 to 
1972 for the coming three years after the merger. D. Mueller studied the return on assets, equity capital profitability. Similar studies on enterprise's accounting data after the merger was also D.Ravenscraft and F. Scherer (Ravenscraf, Scherer, 1989, p. 62), A. Seth, P. M. Healy, A. Ghosh who studied the profitability of the company, which is 315 merged during the period from 1981 to 1995 (Ghosh, 2001, p. 156). Most of the risk factors mentioned in the practical studies have already been studied academic literature. Business consulting studies mainly focus on overcoming practical obstacles learning process and highlight the area in which the involvement of consulting companies provides added value. They are also regards the execution of operational transactions as the decisive criterion for success, which determines the potential impact on performance after the acquisition stage. Therefore, partial vertical integration is profitable since it constitutes a strategic device to relax competition (Fiocco, 2016 , p. 150). Vertical integration brings better coordination within the integrated firm, which boosts its investment incentive at both upstream and downstream levels (Liu, 2016, p. 951). An extensive body of research supports that firms acquire other firms in order to innovate and/or become more sustainable (Park, Krishnan, Chinta, Lee, 2017, p.122). The type of knowledge is a critical distinction for the value of M\&A implementation (Ranucci, Souder, 2015, p. 275). When organizational leaders can no longer achieve their goals through internal growth engines, they often embark on a M\&A (Recardo, Toterhi, 2015, p. 17). M\&A are the important mechanisms through which companies can achieve growth, gain access to new markets and diversify their activities (Savovic, 2017, p. 97). Companies use mergers to increase their stability and improve economic parameters (Sobolev, 2015, p. 2).

\section{Integration}

Most M\&As fail to meet the expectations of the purchasers. It is clear that the due diligence, valuation analysis, and negotiation that precede the closing of a transaction cannot guarantee its success. Instead, the synergies and assumptions that supported the decision to acquire a target business will be realized only if the purchaser effectively integrates the target. Unfortunately, many purchasers either fail to plan the integration of the target adequately or conduct the integration process too slowly (Venema, 2012, p. 50). 


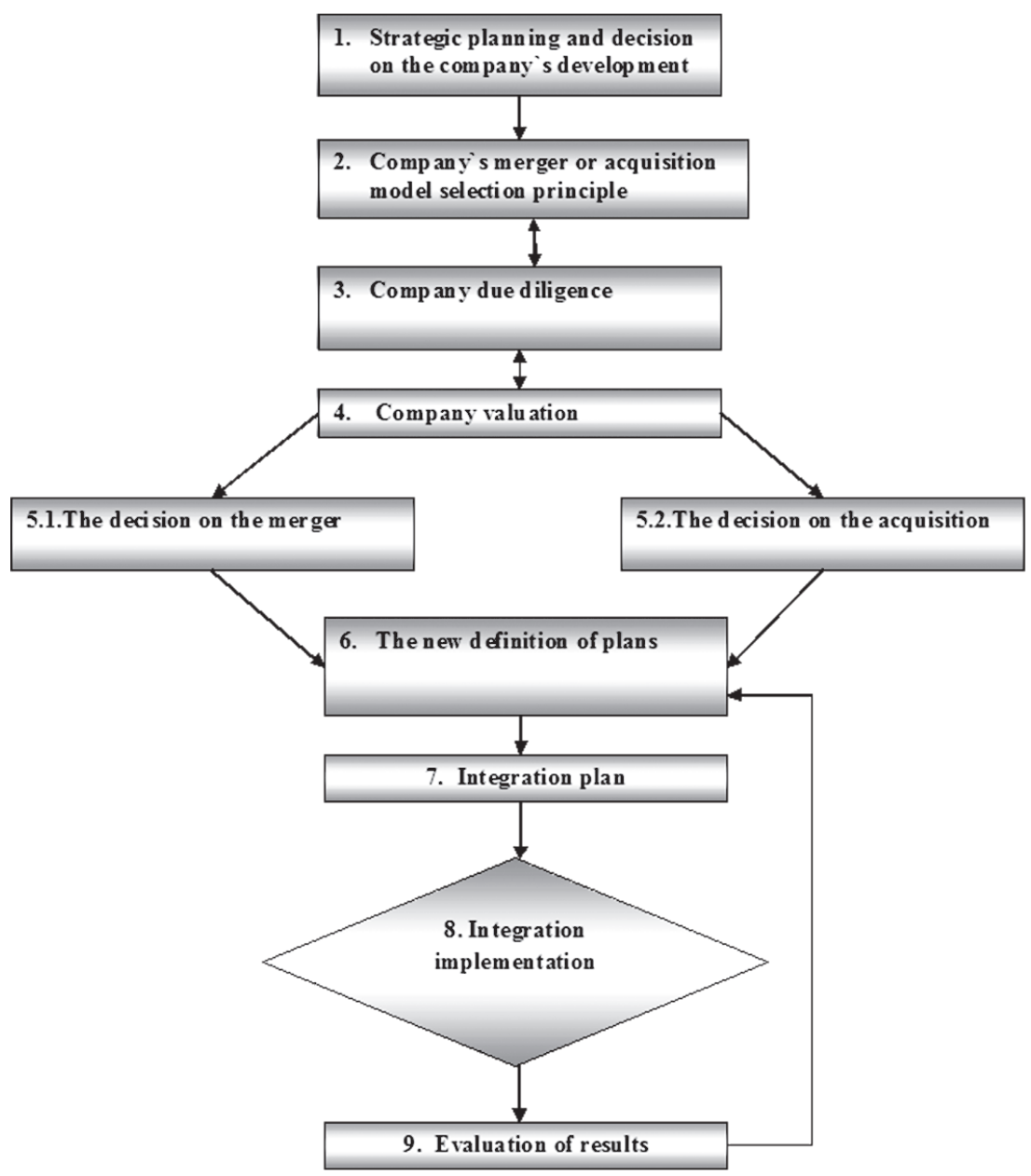

Figure 1. Trade mergers and acquisitions process

Source: author developed

The integration of acquired or merging firms is a key driver of the success or failure of M\&As (Steigenberger, 2017, p. 409). Postmerger integration plays a critical role in M\&A success (Graebner, Heimeriks, Quy, 2017 , p. 4). Managers can plan a successful integration process following a $M \& A$ by selecting the right strategy and managing the integration process (Barros, Dominguez, 2013, p. 983). M\&A success is a function of strategic 
complementarity, cultural fit, and the degree of integration. Strategic complementarity also positively influences cultural fit and the degree of integration. Cultural fit positively influences M\&A success, but surprisingly has a negative impact on the speed and degree of integration. The degree of integration is positively related to speed of integration (Bauer, Matzler, 2014, p. 156).

Author has improved its M\&A management process the approach is based on several stages (see Figure 1).

\section{Strategic planning and decision on the company's development}

Before the head consists of the company's strategic plan it is to take a decision about the direction of development. When deciding on what will be the company's growth strategy, one of the solutions is to M\&A. After the decision all the next step is inherently geared toward change. Strategic decisions are also related to the company's organizational structure. Be responsible for developing an effective development of strategic plans, the company's management to ensure organizational and methodological prerequisites and care should be taken to bring about the development plan objectives and deadlines.

\section{Company's merger or acquisition model selection principle}

Company merger or acquisition means that the company has to choose the appropriate model, under which conditions will be an acquisition / sale or merger. The model is built in accordance with the company's strategic decision on development. Businesses must be able to actively respond to changes in the market. If the company's reorganization plan has been prepared, it is able to change the plan, based on new data, the results of market trends. The reason for the change of plans can also be the company's due diligence results. If they will be significantly different from those planned, the company may decide to change the company's merger plans, and carry out business acquisitions or refuse all of the transaction.

\section{Company due diligence}

Due diligence process usually begins after the agreed in principle on the company's acquisitions. But it is essential that the trial takes place before the transaction becomes irreversible. 


\section{Company valuation}

Company's financial data do not indicate the company's management style and sustainability, market trends, quality of work and other things, which is a very significant development in the long run. The company's value is one of the most important indicators of the business of buying / selling case.

\section{The decision on the merger or acquisition}

Due diligence evaluating data and receiving the company's assessment, it is to decide on the next targets. When the target company has been selected and evaluated, merger or acquisition process is to decide on the transaction price and what kind of payment method you choose - whether payments will be made through its own or borrowed funds cash or shares.

\section{The new definition of plans}

Author offers company managers (owners) to define the new company's short-term and long-term plans, as well as identify new visions and goals of the company. It is defined by the owners of the company with the mergers and acquisitions process wants to achieve. It is necessary to emphasize the new objectives and growth strategy development phase to predict the company's possible solutions.

\section{Integration plan}

Several exploration companies in the integration process were able to reduce the period of uncertainty for their employees, customers and suppliers. The second reason for integration planning is to minimize the cost of the integration process, which depends on other factors. The third reason for integration planning is that it should be started as soon as possible to accelerate the return on investment. As the company's acquisition usually requires large investments, the company's owners and managers want the return of capital from investments in the quickest time. Rapid integration is usually a positive impetus to the company's access to finance in the future. The fourth reason is that the company's management should be given considerable time to make business integration. As the company's managers (owners) take the other important strategic decisions, it reduces the management options to address it directly. Thus, over time, less and less resources are devoted to the integration process, because the company activity to continue in line with market trends. The fifth 
reason is that from a competition point of view, the integration period shortening reduces the time in which the company is exposed to attack competitors. After acquiring the company's competitors are often used in the integration phase, when the body is confusion about their customers in order to convince some customers to switch to them.

Business integration is an essential part of mergers and acquisitions. It depends on the company's management decisions taken before and during integration, and on how these decisions are implemented.

\section{Integration implementation}

Integration stage involves a variety of complex situations and organizational changes in the company, which is a temporary situation of instability and uncertainty. This situation affects the stakeholders business leaders, employees, customers, suppliers. It can interfere with the company's performance. Company's culture is the only one of the factors that affects the company's performance. Assess aspects of the organization (for example, as two competing company employees after the merger will work), or the company's cultural compatibility. This has traditionally been referred to as one of the most typical reasons for mergers and acquisitions is not sufficiently - often after the transaction process is a significant effort to reinvigorate the company, reproduced in the buyer's corporate culture, rather than to create a new culture that would be more appropriate for both companies. Motivate employees to participate in organizational change process, both before and after mergers and acquisitions transaction implementation. Significant organizational changes within the company explained.

Leadership and talent retention are critical HR-related components in post-M\&A integration, but the extent to which these factors interact with each other and eventually contribute to the success of post-M\&A integration is under-explored (Zhang, Ahammad, Tarba, Cooper, Glaister, Wang, 2015, p. 1021). Despite increasing attention from scholars, only a handful of studies have actually investigated M\&A processes (Friedman, Carmeli, Tishler, Shimizu, 2016, p. 2339). Existing studies have suggested the need of effective social cultural integration post acquisition for the success of M\&A of culturally distant firms. Existing literature indicates cultural difference between merging organization as one of the factors for the poor performance of M\&A (Jha, 2015, p. 25). The positive aspects of cultural differences and suggests that a lot can be gained from dealing with attractive cultures, even when they are different. Managers of acquiring/ merging firms can identify whether their employees find the partner's culture desirable, and if they do, proceed with the takeover and then 
adopt the partner's organizational routines during post-merger integration (Li, Brodbeck, Shenkar, Ponzi, Fisch, 2017, p. 951).

\section{Evaluation of results}

In order to assess M\&A results are compared company performance before and after mergers and acquisitions transactions. Another comparison is between the company and other similar competitors in the industry, who has not completed a merger in the same period.

Speed of integration is an important success factor for acquisitions (Bauer, King, Matzler, 2016., p. 161). Successful M\&A depend on the partners involved in the transaction. Many scholars and practitioners argue that the most difficult to combine the company culture, and these differences are one of the main reasons why many transactions experiencing failure. The author believes that it is important to carefully investigate possible combinations both financially and culturally from an early stage. Business strategic differences can create synergies and improve the competitiveness of the new company. However, the reality is that it is often difficult to predict beyond that specific period of time is necessary in order to achieve good results in the merger at the earliest possible stage. The author emphasizes that the company's success depends on its ability to create added value after the merger has taken place. For this success key author considers the integration process management. Integration main goal is to make more efficient use of existing facilities. The merging company in the integration process is very important to get the maximum benefit from the acquisition. On the one hand, it is necessary for the success of integration on the other hand; the integration will lead to cultural clashes and therefore interfere with the merger.

\section{Conclusions}

The company is responsible at the European Commission's position is in unity with the success of the company. If the company's activities comply with the social aspects that contribute to customer requirements, the ability to provide a parallel to the other community members such as employees, suppliers, local communities are respected. This in turn means that a positive force in society can bring direct benefit and ensure long-term competitiveness. Today's requirement is that businesses and organizations need a sane, professional manager. The driver, also a businessman, professional skills not only to work with the company's economic information (financial records, analysis, control, forecasting). The driver must also be able to take decisions in the management of 
human resources, which the absence of economic and legal information is also necessary psychological, pedagogical, ethical and social basis. As the surveys show, the acquirer should consider using a consistent and scalable process evaluating such typical risks associated with M\&A. This means giving the same meaning checking the legality of reputation as a legal, financial, operational and other traditional credibility check. Move to the next level of due diligence needs to be improved more than replacing the traditional credibility test activities. However, every M\&A has its own personality and thus the process of expanding legality may vary depending on the situation.

\section{REFERENCES}

1. Banulescu, V., Popescu-Cruceru, A., Leuciuc, E. G. Consideration on the Legal Regime of the Mergers and Acquisition. Romanian Statistical Review. 2012, 4, 209-215 p.

2. Barkema, H. G., Schijven, M. How do firms learn to make acquisitions? Journal of Management. Vol. 34(3), 2008. - 594-634 p.

3. Barros, R. H., Dominguez I. L. Integration strategies forthe success of mergers and acquisitions in financial services companies. Journal of Business Economics $\mathcal{G}$ Management. 2013, 14, 979-992 p.

4. Bauer, F., King, D., Matzler, K. Speed of acquisition integration: Separating the role of human and task integration. Scandinavian Journal of Management. 2016, 32, $150-165 \mathrm{p}$.

5. Bauer, F., Matzler, K. Antecedents of M\&A success: The role of strategic complementarity, cultural fit, and degree and speed of integration. Strategic Management Journal. 2014, 35, 269-291 p.

6. Canina, L., Jin-Young, K., Qingzhong, M. What We Know about M\&A Success. Cornell Hospitality Quarterly. 2010, 51, 81-101 p.

7. Chang, S. I., Chang, I. C., Wang, T. Information systems integration after merger and acquisition. Industrial Management \& Data Systems. Vol. 2014, 114, 37-52 p.

8. Cullinan, G., Le Roux, J. M., Weddigen, R. M. When to walk away from a deal. Harward Business Review. Vol. 82 (4). 2004. - 96-104 p.

9. Fiocco, R. The strategic value of partial vertical integration. Proceedings: Ioannina Meeting on Applied Economics \& Finance. 2016. - 150-151 p.

10. Friedman, Y., Carmeli, A., Tishler, A., Shimizu, K. Untangling micro-behavioral sources of failure in mergers and acquisitions: a theoretical integration and extension. International Journal of Human Resource Management. 2016, 27, 2339-2369 p.

11. Ghosh, A. Does operating performance really improve following corporate acquisitions? Journal of Corporate Finance. Vol. 7. 2001. - 151-178 p.

12. Graebner, M. E., Heimeriks, K. H., Quy, N. H., Vaara, E. The process of postmerger integration: A review and agenda for future research. Academy of Management Annals. 2017, 11, 1-32 p. 
13. Harvey, M. G., \& Lusch, R. F. Expanding the nature and scope of due diligence. Journal of Business Venturing. Vol. 10. 1995. - 5-21 p.

14. Hitt, M. A., King, D., Krishnan, H., Makri, M., Schijven, M., Shimizu, K., \& Zhu, H. Mergers and acquisitions: Overcoming pitfalls, building synergy, and creating value. Business Horizons. Vol. 52(6). 2009. - 523-529 p.

15. Jain, P. Strategic Role of HR in Mergers and Acquisitions. Aweshkar Research Journal. 2014, 17, 97-99 p.

16. Jha, J. K. Effect of Cultural Differences on Performance of Merger and Acquisition via Psychological Safety: A Framework. OPUS: HR Journal. 2015, 6, 18-37 p.

17. Kernstock, J., Brexendorf, T. Corporate Brand Integration in Mergers and Acquisitions - An Action Research-Based Approach. Corporate Reputation Review. 2012, 15, 169-178 p.

18. Kim, J. H. Asset specificity and firm value: Evidence from mergers. Journal of Corporate Finance. 2018, 48, 375-412 p.

19. March, J. G. Exploration and exploitation in organizational learning. Organization Science. Vol. 2(1). 1991. - 71-87p.

20. McGrady, S. Extending due diligence to improve mergers and acquisitions. Bank Accounting and Finance. Vol. 18(4). 2005. - 17-23 p.

21. Li, C., Brodbeck, F. C., Shenkar, O., Ponzi, L. J., Fisch, J. H. Embracing the foreign: Cultural attractiveness and international strategy. Strategic Management Journal. 2017, 38, 950-971 p.

22. Liu, X. Vertical integration and innovation. International Journal of Industrial Organization. 2016, 47, 88-120 p.

23. Park, D., Krishnan, H. A., Chinta, R., Lee, M. After Acquiring Innovation and Sustainability: Executive Effects. Journal of Business Inquiry: Research, Education \& Application. 2017, 16, 112-130 p.

24. Pratt, S. P., Reilly, R. F., Schweihs, R. P. Valuing Small Businesses and Professional Practices. Third Edition. New York - McGraw-Hill, 1998. - 887 p.

25. Ranucci, R. A., Souder, D. Facilitating tacit knowledge transfer: routine compatibility, trustworthiness, and integration in M\&As. Journal of Knowledge Management. 2015, 19, 257-276 p.

26. Ravenscraft, D. J., Scherer, F. M. Mergers, sell-offs \& economics efficiency. Washington: The Brooking Institution. 1987. - 290 p.

27. Recardo, R. J., Toterhi, T. Strategic Integration: How to Realize the Value of an Acquisition. Global Business \& Organizational Excellence. 2015, 35, 6-22 p.

28. Savovic, S. The impact of the dimensions of transformational leadership no the post - acquisition performance of the acquired company. Economic Horizons / Ekonomski Horizonti. 2017, 13, 97-109 p.

29. Schuler, R., \& Jackson, S. HR issues and activities in mergers and acquisitions. European Management Journal. Vol. 19(3). 2001. - 239-253 p.

30. Sobolev, L. Horizontal integration or conglomeration? Economic Analysis. 2015, 24, 2-11 p.

31. Steigenberger, $N$. The Challenge of Integration: A Review of the M\&A Integration Literature. International Journal of Management Reviews. 2017, 19, 408-431 p. 
32. Vazirani, N. An Integrative Role of HR in Handling Issues Post Mergers and Acquisitions. SIES Journal of Management. 2013, 9, 82-88 p.

33. Venema, W. H. Integration: The critical M\&A success factor. Journal of Corporate Accounting \& Finance (Wiley). 2012, 23, 49-53 p.

34. Very, P., \& Schweiger, D. M. The acquisition process as a learning process: Evidence from a study of critical problems and solutions in domestic and cross-border deals. Journal of World Business. Vol. 36(1). 2001. - 11-31 p.

35. Zhang, J., Ahammad, M. F., Tarba, S., Cooper, C. L., Glaister, K. W., Wang, J. The effect of leadership style on talent retention during Merger and Acquisition integration: evidence from China. International Journal of Human Resource Management. 2015, 26, 1021-1050 p. 